\title{
Required ozone doses for removing pharmaceuticals from wastewater effluents
}

Antoniou, Maria; Hey, Gerly; Rodríguez Vega, Sergio; Spiliotopoulou, Aikaterini; Fick, Jerker; Tysklind, Mats; la Cour Jansen, Jes; Andersen, Henrik Rasmus

\section{Published in:}

Science of the Total Environment

Link to article, DOI:

10.1016/j.scitotenv.2013.03.072

Publication date:

2013

Link back to DTU Orbit

Citation (APA):

Antoniou, M., Hey, G., Rodríguez Vega, S., Spiliotopoulou, A., Fick, J., Tysklind, M., la Cour Jansen, J., \& Andersen, H. R. (2013). Required ozone doses for removing pharmaceuticals from wastewater effluents. Science of the Total Environment, 456-457, 42-49. https://doi.org/10.1016/j.scitotenv.2013.03.072

\section{General rights}

Copyright and moral rights for the publications made accessible in the public portal are retained by the authors and/or other copyright owners and it is a condition of accessing publications that users recognise and abide by the legal requirements associated with these rights.

- Users may download and print one copy of any publication from the public portal for the purpose of private study or research.

- You may not further distribute the material or use it for any profit-making activity or commercial gain

- You may freely distribute the URL identifying the publication in the public portal 


\title{
Required ozone doses for removing pharmaceuticals from wastewater effluents
}

\author{
Maria G. Antoniou ${ }^{1,2}$, Gerly Hey ${ }^{3}$, Sergio Rodríguez Vega ${ }^{4}$, Aikaterini Spiliotopoulou ${ }^{1}$, \\ Jerker Fick ${ }^{5}$, Mats Tysklind ${ }^{5}$, Jes la Cour Jansen ${ }^{3}$, and Henrik Rasmus Andersen ${ }^{1, *}$
}

\footnotetext{
${ }^{1}$ Department of Environmental Engineering, Technical University of Denmark, Miljøvej, Building 113, 2800 Kongens Lyngby, Denmark .

${ }^{2}$ Department of Environmental Science and Technology, Cyprus University of Technology, PO Box: 50329, 3603 Lemesos, Cyprus.

${ }^{3}$ Water and Environmental Engineering at Department of Chemical Engineering, Lund University, P.O. Box 124, SE-221 00 Lund, Sweden.

${ }^{4}$ Departamento de Ingeniería Química, Facultad de Ciencias Químicas, Universidad Complutense Madrid, 28040 Madrid, Spain.

${ }^{5}$ Department of Chemistry, Umeå University, SE-90187 Umeå, Sweden.

*Corresponding authors e-mail: henrik@ndersen.net
}

\begin{abstract}
The aim of the thisstudy was to investigate the ozone dosage required to remove active pharmaceutical ingredients (APIs) from biologically treated wastewater of varying quality, originated from different raw wastewater and wastewater treatment processes.

Secondary effluents from six Swedish wastewater treatment plants (WWTP) were spiked with 42 APIs (nominal concentration $1 \mu \mathrm{g} / \mathrm{L}$ ) and treated with different $\mathrm{O}_{3}$ doses $(0.5-12.0$ $\mathrm{mg} / \mathrm{L}$ ozone) in bench-scale experiments.

In order to compare the sensitivity of APIs in each matrix, the specific dose of ozone required to achieve reduction by one decade of each investigated API $\left(\mathrm{DDO}_{3}\right)$ was determined for each effluent by fitting a first order equation to the remaining concentration of API at each applied ozone dose. Ozone dose requirements were found to vary significantly between effluents depending on their matrix characteristics.

The specific ozone dose was then normalized to the dissolved organic carbon (DOC) of each effluent. The $\mathrm{DDO}_{3} / \mathrm{DOC}$ ratios were comparable for each API between the effluents.

15 of the 42 investigated APIs could be classified as easily degradable ( $\left.\mathrm{DDO}_{3} / \mathrm{DOC} \leq 0.7\right)$, while 19 were moderately degradable $\left(0.7<\mathrm{DDO}_{3} / \mathrm{DOC} \leq 1.4\right)$, and 8 were recalcitrant towards $\mathrm{O}_{3}$-treatment $\left(\mathrm{DDO}_{3} / \mathrm{DOC}>1.4\right)$. Furthermore, we predict that a reasonable estimate of the ozone dose required to remove any of the investigated APIs may be attained by multiplying the experimental average $\mathrm{DDO}_{3} / \mathrm{DOC}$ obtained with the actual DOC of any effluent.
\end{abstract}

Keywords: matrix effect; ozonation; ozone dose, pharmaceuticals; wastewater. 


\section{Introduction}

The modern life-style of developed countries involves daily usage of artificial compounds such as active pharmaceutical ingredients (API), personal care products, hormones, pesticides and other environmentally persistent chemicals. As a result residues of these compounds become micropollutants in wastewater (Fick et al., 2010; Hollender et al., 2009; Richardson, 2010; Gerrity and Snyder, 2011; Huber et al., 2005; Richardson, 2010). Of all groups of micropollutants the vast majority of research activities are currently focused on the fate of active pharmaceutical ingredients during wastewater treatments (Hollender et al., 2009; Huber et al., 2003; Huber et al., 2005; Lee and von Gunten, 2010; Zimmermann et al., 2011; Fick et al., 2011; Falås et al., 2012a, 2012b). APIs by purpose are generally designed to illicit a specific biological action. Due to their use pattern, release to the environment is mainly via sewage outlets into surface waters. APIs are usually found at concentrations ranging from $\mathrm{pg} / \mathrm{L}-\mu \mathrm{g} / \mathrm{L}$ in wastewater and surface waters influenced by wastewater outlets. However, chronic exposure of APIs to humans and wildlife even at these low concentrations is both of scientific and societal concern (Richardson, 2010).

To address this problem many WWTPs consider incorporating an additional treatment process step to remove APIs from the effluent. Treatment with $\mathrm{O}_{3}$ appears to be one of the most promising technologies for the removal of these compounds (Ternes et al., 2003. Hansen et al., 2010; Hollender et al., 2009; Huber et al., 2003; Huber et al., 2005; Lee and von Gunten, 2010; Zimmermann et al., 2011).

One of the first studies which showed the efficiency of ozonation for removal of micropollutants in biological treated wastewater was by Ternes et al. (2003). Ozonation was employed at 5.0 to $15.0 \mathrm{mg} / \mathrm{L}$ of $\mathrm{O}_{3}$ to investigate the removal efficiency (Ternes et al., 2003) for selected APIs, personal care products and iodated X-ray contrast media. Pharmaceuticals and personal care products were removed sufficiently by only $5 \mathrm{mg} / \mathrm{L}$ of $\mathrm{O}_{3}$ while the iodated $\mathrm{X}$-ray contrast media were only partially removed by $15 \mathrm{mg} / \mathrm{L}$ of $\mathrm{O}_{3}$. However, as there is not much toxicological concern for iodated X-ray contrast media results were interpreted as promising and more optimised treatment studies were conducted which reported efficient removal of pharmaceuticals and hormones in wastewater at lower $\mathrm{O}_{3}$ doses (2.0-3.5 mg/L) (Bahr et al., 2007; Hansen et al., 2010; Huber et al., 2005). Estimating the removal efficiencies of APIs from wastewater effluents in bench and pilot scale experiments, was the main focus of subsequent studies (Hollender et al., 2009; Huber et al., 2003; Zimmermann et al., 2011). For example, Hollender et al. (2009) studied the removal efficiencies of 220 pharmaceuticals in full scale with conventional activated sludge sewage treatment followed 
by ozonation and sand filtration. Kinetic studies and modeling of ozonation based on reactor hydraulics, $\mathrm{O}_{3}$ chemistry and reaction kinetics were also performed for a full scale municipal wastewater facility (Zimmermann et al., 2011).

Generally, APIs and other micropollutants are easy to degrade, i.e. can be removed with low ozone dosage, if they react reasonable fast with molecular ozone. If a micropollutant does not react well with ozone it will still degrade with higher applied ozone dosage via a secondary oxidation mechanism by which $\mathrm{O}_{3}$ in water is converted to the hydroxyl radical, $\mathrm{HO}^{\bullet}$, which is very reactive (non-selective) to most organic molecules.

Up to now, the parameter most commonly used by researchers to determine how well an API reacts with $\mathrm{O}_{3}$, is the second order rate constant with $\mathrm{O}_{3}\left(k_{O 3, A P I}\right.$, selective oxidation) and $\mathrm{HO}^{\bullet}$ ( $k_{H O, A P I}$, non-selective oxidation) (Hollender et al., 2009; Huber et al., 2003; Zimmermann et al., 2011). According to these studies, compounds with $k_{O 3, A P I}$ greater than $10^{4} \mathrm{M}^{-1} \mathrm{~s}^{-1}$, require low delivered $\mathrm{O}_{3}$ doses (easily degraded). Compounds with $k_{O 3, A P I}<10^{4}$ $\mathrm{M}^{-1} \mathrm{~s}^{-1}$, are more persistent to $\mathrm{O}_{3}$ treatment and therefore their degradation occurs mainly via reaction with $\mathrm{HO}^{\bullet}$, the secondary degradation route of ozonation.

However, of the several hundred APIs which have been detected in WWTP effluents (Ternes et al., 1998; Kolpin et al., 2002; Hollender et al., 2009; Fick et al., 2011; Falås et al., 2012) very few have had their respective $k_{O 3, A P I}$ and $k_{H O \bullet A P I}$ determined (Benner and Ternes, 2009; Buffle et al., 2006a; Dodd et al., 2006; Huber et al., 2003; Huerta-Fontela et al., 2011). In fact, constants are available for less than $10 \%$ of the model APIs used in this study (Table $\mathrm{S} 2)$. Even when these two rate constants $\left(k_{O 3, A P I}\right.$ and $\left.k_{H O, A P I}\right)$ are known for an API, an experiment to determine the ozone and HO exposure that results from an ozone dose in the specific wastewater is needed before the degradation of the API can be predicted (Huber et al., 2005; Buffle et al., 2006b).

With $\mathrm{O}_{3}$ production being an energy intensive process (Kim and Tanaka, 2011), it is important for WWTPs to use optimum $\mathrm{O}_{3}$ doses that achieve sufficient API degradation while maintaining low operational cost (Bahr et al., 2007; Hansen et al., 2010). APIs exhibit different susceptibilities to $\mathrm{O}_{3}$ degradation which can vary up to 10 orders of magnitude (Hoigne and Bader, 1983; Hollender et al., 2009; Huber et al., 2003). They are also competing for $\mathrm{O}_{3}$ degradation with the organic components found in the matrix of the WWTP effluent (Hollender et al., 2009) that vary in amount and quality depending on the treatment process and origin of wastewater. This makes it particularly difficult to predict the required 
$\mathrm{O}_{3}$ dosage requirements $\left(\mathrm{DO}_{3}\right)$ for satisfactory API removal in WWTP effluents, which is a crucial parameter in estimating treatment design and therefore cost.

Therefore, this study aimed to unveil a more direct approach to describe the removal of pharmaceuticals in wastewater effluents, which could also be used to predict the required $\mathrm{O}_{3}$ dose for $90 \%$ removal of a specific pharmaceutical in a wastewater, solonly based on simple water quality parameters. To achieve this, the required delivered $\mathrm{O}_{3}$ dose $\left(0.5 \mathrm{mg} / \mathrm{L} \leq \mathrm{DO}_{3} \leq\right.$ $\sim 12 \mathrm{mg} / \mathrm{L}$ ) to achieve one order of magnitude removal of 42 APIs (at low concentrations, $\mu \mathrm{g} / \mathrm{L}$, Table S2) from 6 Swedish WWTP effluents, were investigated. These APIs are commonly found in the WWTP effluents of Sweden (Fick et al., 2011, 2012; Falås et al., 2012a) and have different susceptibilities to ozonation (Benner and Ternes, 2009; Buffle et al., 2006a; Dodd et al., 2006; Hoigne and Bader, 1983; Huber et al., 2003).

Effluents used in the experiments were chosen to represent typical variations observed in the main traditional characteristics of effluent quality that would occur due to different treatment processes currently employed in Sweden and also variability in raw water, i.e. COD, alkalinity and $\mathrm{N}-\mathrm{NH}_{4}{ }^{+}$content (Table 1).

As API's begin to react with $\mathrm{O}_{3}$, they are also competing with the matrix components of the effluent for $\mathrm{O}_{3}$ degradation, therefore this study attempted to correlate the $\mathrm{DO}_{3}$ with the effluent characteristics.

\section{Materials and Methods}

\subsection{Chemicals}

All pharmaceutical reference standards were of analytical grade $(>98 \%)$ purchased from different suppliers (Table S3). A stock solution of the APIs was prepared in methanol (Merck, Darmstadt, Germany) at concentration of about $100 \mathrm{mg} / \mathrm{L}$. The experimental set-up for the ozonation was based on a $1.0 \mathrm{~g} / \mathrm{h}$ ozone generator from $\mathrm{O}_{3}$-Technology $\mathrm{AB}$,Vellinge, Sweden, which was supplied with dry oxygen gas. The generated $\mathrm{O}_{3}$ was dispersed though a diffuser in a collection bottle containing Milli-Q water. The later one was immersed in an icebath sot that $\mathrm{O}_{3}$ solubility is increased. Based on these experimental conditions, the concentration of $\mathrm{O}_{3}$ in the stock solution was between 30 and $40 \mathrm{mg} / \mathrm{L}$. Further details are found in Antoniou and Andersen (2012).

\subsection{Wastewater effluents}

Effluents from five WWTPs in Sweden, including Källby (Effluent 1\&2), Björnstorp (Effluent 3), Oresundsverket (Effluent 4), Sjölunda (Effluent 5), and Nykvarnsverket 
(Effluent 6) were used in this study. Effluent 1 and Effluent 2 were from the same treatment plant but were collected on separate occasions with a 3 week time interval. Although Effluent 1 and Effluent 2 come from the same WWTP, they were treated as 2 different effluents due to the variability of their characteristics. This difference is attributed to the significant rainfall events which occurred following the first sampling event. Continues rainfall most likely caused a sludge wash-out, reducing the biological treatment efficiency and increasing the COD value, while at the same time alkalinity value reduced because of dilution with the rain water. The characteristics and treatment processes that are performed at each WWTP are listed in Table 1 and extensively described in S.I., respectively. As nitrification was well functioning in all WWTPs, the measured concentration of nitrite in the effluents was below $0.1 \mathrm{mg} / \mathrm{L}$.

Table 1. Source and characterization of the wastewater effluents.

\begin{tabular}{lcccccc}
\hline WWTP & $\begin{array}{c}\text { Källby 1 } \\
\text { Eff1 }\end{array}$ & $\begin{array}{c}\text { Källby 2 } \\
\text { Eff2 }\end{array}$ & $\begin{array}{c}\text { Björnstorp } \\
\text { Eff3 }\end{array}$ & $\begin{array}{c}\text { Öresundsverket } \\
\text { Eff4 }\end{array}$ & $\begin{array}{c}\text { Sjölunda } \\
\text { Eff5 }\end{array}$ & \multicolumn{2}{c}{ Nykvarnsverket } \\
& 29 & 51 & 30 & 36 & 90 & 44 \\
\hline $\mathrm{COD}, \mathrm{mg} / \mathrm{L}$ & 7.5 & 6.5 & 5.2 & 8.1 & 13.7 & 8.4 \\
DOC, mg/L & 244 & 154 & 185 & 229 & 256 & 164 \\
Alkalinity, $\mathrm{mg} \mathrm{HCO}_{3}{ }^{-} / \mathrm{L}$ & 6.6 & 6.7 & 7.0 & 7.2 & 6.7 & 6.8 \\
$\mathrm{pH}$ & 1.36 & 2.98 & 0.77 & 4.93 & 1.86 & 5.98 \\
$\mathrm{~N}^{-N H_{4}}{ }^{+}, \mathrm{mg} / \mathrm{L}$ & 2.74 & 2.94 & 2.07 & 2.10 & 1.86 & 2.01 \\
$\mathrm{SUVA}(\mathrm{L} / \mathrm{mg}) / \mathrm{m}$ & 0.206 & 0.190 & 0.107 & 0.171 & 0.256 & 0.168 \\
$\mathrm{~A} 254, \mathrm{~cm}^{-1}$ & & & & & &
\end{tabular}

\subsection{Experimental set-up}

Effluent was spiked with the APIs standard to give a nominal concentration of $1 \mu \mathrm{g} / \mathrm{L}$, and then transferred into borosilicate glass vials, where different volumes of $\mathrm{O}_{3}$ stock solution were added (in triplicate) to give nominal concentrations between 0.5 and $<12 \mathrm{mg} / \mathrm{L} \mathrm{O}_{3}$ for a total volume of $150 \mathrm{~mL}$. Vials were then placed in a covered waterbath at $15^{\circ} \mathrm{C}$ for at least 10 hours which is significantly more than the lifetime of $\mathrm{O}_{3}$ in wastewater. The doses of $\mathrm{O}_{3}$ delivered in each experiment varied ( $\sim 5 \%$ relative standard deviation, RSD) since the concentration of $\mathrm{O}_{3}$ in the stock solution was variable between days, but the delivered $\mathrm{O}_{3}$ dose to the vials was quantified exactly by adding the same volume of ozone stock solution to vials prepared with indigo trisulfonate solutions as was added to the effluents. The loss of indigo trisulfonate is proportional to the $\mathrm{O}_{3}$ mole to mole. Further details of the ozonation procedure and quantification is given in Antoniou and Andersen, 2012. Over several method evaluation performed in parallel to the experiments using each time several vials prepared with indigo trisulfonate solutions the repeatability of the added $\mathrm{O}_{3}$ dose was always better than $5 \%$ RSD. 


\subsection{Analysis}

DOC, $\mathrm{pH}$, alkalinity $\left(\mathrm{mg} \mathrm{HCO}_{3}{ }^{-} / \mathrm{L}\right), \mathrm{COD}$, and $\mathrm{NH}_{4}{ }^{+}$concentrations in the effluent were quantified based on standard methods. UV-absorbance at 254 and $272 \mathrm{~nm}$ was measured before and after ozonation with a Varian CARY 50Bio UV-Vis spectrophotometer. Specific UV-absorbance (SUVA) was determined by dividing the sample absorbance at $\lambda=254 \mathrm{~nm}$ with the corresponding DOC value. The specific $\mathrm{O}_{3}$ dose delivered $\left(\mathrm{DO}_{3}\right)$ was measured with the colorimetric method of indigo $(\lambda=600 \mathrm{~nm})$, by preparing bottles with indigo trisulfonate solution in Milli-Q water in parallel with the treatment samples (Antoniou and Andersen, 2011; Bader and Hoigne, 1981). After SPE extraction, the APIs were quantified by LC/MS/MS using a triple-stage quadrupole mass spectrometer (MS/MS TSQ Quantum Ultra EMR) coupled to an Accela LC pump (both from Thermo Fisher Scientific, San Jose, CA, USA) and a PAL HTC autosampler (CTC Analytics AG, Zwingen, Switzerland) with a Hypersil GOLD aQ ${ }^{\mathrm{TM}}$ column (50 mm x $2.1 \mathrm{~mm}$ ID x $5 \mu \mathrm{m}$ particles). The same method was used to investigate the fate of APIs in wastewater treatment by Hörsing et al. (2011) and Hey et al. (2012) and a full method evaluation and detailed description is given in Grabic et al. (2012).

\subsection{Data treatment}

In order to determine the $\mathrm{O}_{3}$ dose that achieved $90 \%$ removal of each API in every effluent, the removal rate achieved with each $\mathrm{O}_{3}$ dose in each effluent were fitted with Equation 1. Equation 1 is an exponential formula that describes the remaining API concentration in relation to its initial concentration after a specific $\mathrm{O}_{3}$ dose is delivered $\left(\mathrm{DO}_{3}\right)$. It is dependent on the fact that ozone's fate in the effluent is determined by the effluent's matrix and not significantly affected by the reaction with the APIs; therefore is independent from the APIs concentration. The equation contains the $\mathrm{O}_{3}$ dose required to remove $90 \%$ of the API as a constant (here noted as decadic dose of $\mathrm{O}_{3} D D O_{3}$ ), allowing determination of the standard error directly through curve fitting. The fitted parameter is named the decadic dose of $\mathrm{O}_{3}$, $\mathrm{DDO}_{3}$.

(Eq.1) $\log \left(\frac{C}{C_{o}}\right)=\frac{-D O_{3}}{D D O_{3}} \Leftrightarrow C=C_{o} \cdot 10^{-\left(\frac{D O_{3}}{D D O_{3}}\right)}$

Equation 1 resembles the general formula used for the characterization of the effectiveness of energy intensive advanced treatment methods (Equation 2) recommended by IUPAC and described by Bolton et al. (2001). Equation 2 correlates the electrical energy dose (EED) with 
the residual concentration of the treatment target compound and uses the constant $E_{E O}$ which is the $E E D$ required to achieve $90 \%$ removal (Bolton et al., 2001).

(Eq.2) $\log \left(\frac{C}{C_{o}}\right)=\frac{-E E D}{E_{E O}}$

Equation 1 was suggested by Hansen et al., (2010) who used both Equations 1 and 2 to describe the effectiveness of $\mathrm{O}_{3}$ treatment for estrogenic chemicals in WWTP effluents in terms of the $\mathrm{O}_{3}$ and energy dosage applied. Based on the above, it was decided to use the same system of equations to describe the effectiveness of $\mathrm{O}_{3}$-treatment for API removal from wastewater. Data treatment (determination of $\mathrm{DDO}_{3}$ ) was conducted in GraphPad Prism 5.

\section{Results and Discussion}

\subsection{Removal of APIs from 6 WWTP effluents: Effect of wastewater matrix}

In this study, 42 APIs commonly found in WWTP effluents in Sweden were spiked in six different WWTP effluents and treated with $\mathrm{O}_{3}$ to evaluate their removal efficiencies and the effect of the matrix. Figure 1 summarizes the contribution of each $\mathrm{O}_{3}$ dose $(0.5$ to $\sim 12.0 \mathrm{mg} / \mathrm{L}$ $\mathrm{O}_{3}$ ) on the removal of the APIs in each one of the six WWTP effluents. The order with which APIs appear in the $x$-axis is with declining order of percentage removal achieved with the lowest $\mathrm{O}_{3}$ dose. The same data is also shown in Figure 2 (few examples) and Figures $\mathrm{S} 1$ to S6, but plotted in a less condensed manner allowing representation of experimental variation. A general trend can be seen whereby increasing $\mathrm{O}_{3}$ dosage increases API removal efficiency (Figure 1). However, great variability is observed in required $\mathrm{O}_{3}$ dose to achieve removal of different APIs within the same effluent and for the same API between effluents.

For the lowest delivered $\mathrm{O}_{3}$ dose $(0.5-0.6 \mathrm{mg} / \mathrm{L})$, Effluent 1 and Effluent 3 had the highest number of APIs exhibiting removal efficiencies between 50-100\%, possibly due to their low COD values compared to other effluents. Low COD values reduce the competition for $\mathrm{O}_{3}$ between APIs and organic matter of the matrix required for degradation. The high alkalinity value observed in Effluent 1(highest in the group, Table 1) did not seem to significantly affect API removal. However, APIs in Effluent 5 appear to be the most recalcitrant to $\mathrm{O}_{3}$ treatment, with all exhibiting $<50 \%$ removal at the lowest delivered $\mathrm{O}_{3}$ dosage. A significant increase in $\mathrm{O}_{3}$ dosage to $\sim 8.9 \mathrm{mg} / \mathrm{L}$, had little effect on API removal in Effluent 5 compared to the other effluents, since only 18 out of 42 were removed by levels greater than $90 \%$. It is believed that both high COD $(\sim 90 \mathrm{mg} / \mathrm{L})$ and alkalinity $(\sim 250 \mathrm{mg}$ $\mathrm{HCO}_{3}{ }^{-} / \mathrm{L}$ ) levels present in Effluent 5 contributed to inhibiting the API removal. 

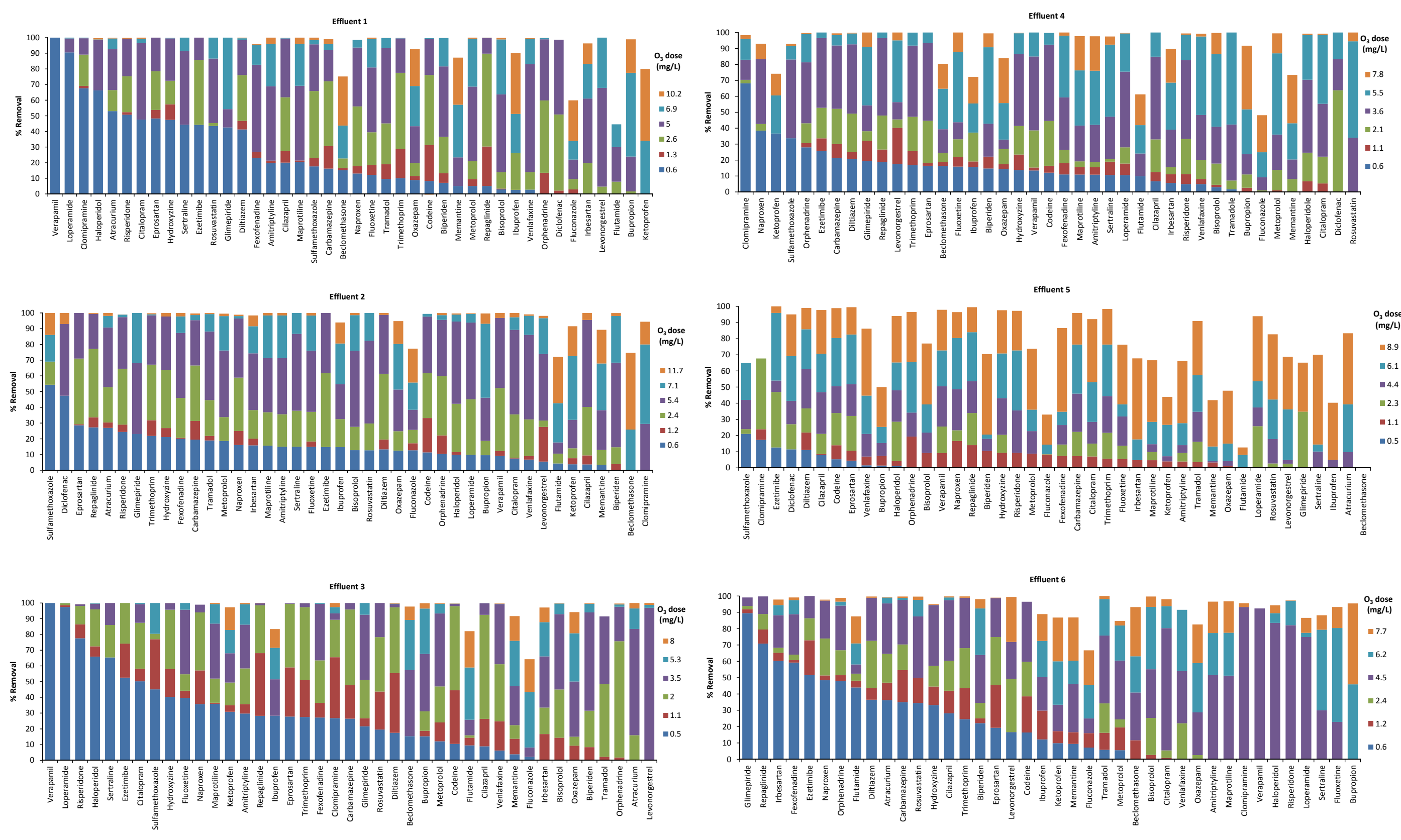

Figure 1: Profiles of dose dependency for the removal of pharmaceuticals in the 6 investigated wastewaters. 
Overall, all APIs in Effluents 2, 3, and 6 were removed by over $50 \%$ at the highest $\mathrm{O}_{3}$ dosage. In Effluents 1 and 4, only 1 API had less than 50\% removal, while 7 APIs were poorly removed $(<50 \%)$ in Effluent 5 even at the highest $\mathrm{O}_{3}$ dosage.

Based on the results shown in Figure 1, an APIs' susceptibility to $\mathrm{O}_{3}$ degradation appears to be highly dependent on the type of wastewater used, explaining the wide range of removal efficiencies that some APIs exhibited in this study. Specifically, the synthetic steroid beclomethasone was removed between $0-98 \%$ in the 6 effluents. Removal of fluconazole (antifungal) and flutamide (antiandrogen) ranged between 33-77\% and 13-87\%, respectively, inferring that some APIs were not effectively degraded (to reach the treatment goal of $90 \%$ ) in any of the tested- effluents with the applied $\mathrm{O}_{3}$ doses.

A
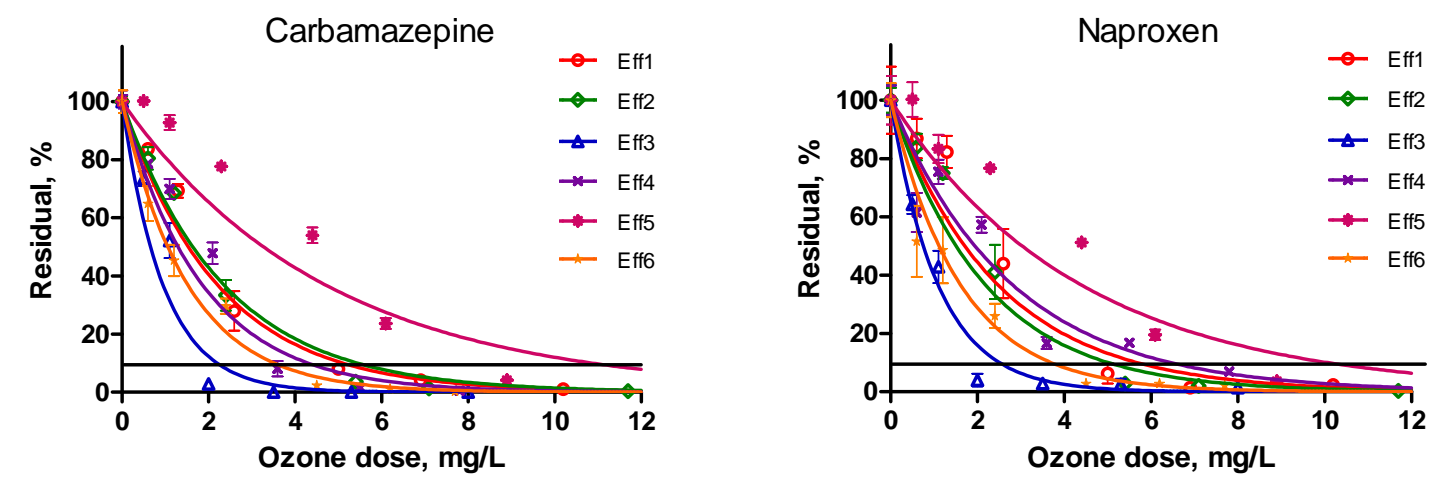

B
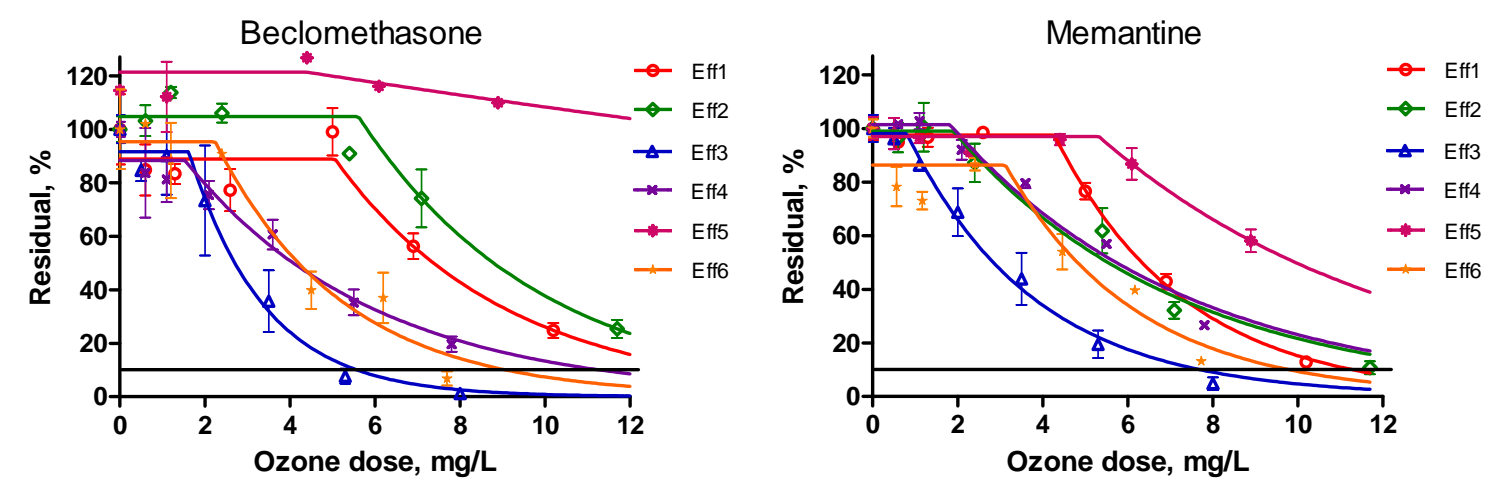

Figure 2: Concentration profiles for selected APIs in different WWTP effluents, which follow first order decay with the delivered $\mathrm{O}_{3}$ dose $\left(\mathrm{DO}_{3}\right)$ (A) or exhibiting an apparent lag-phase (B). The intersect of the black horizontal line with the $10 \%$ remaining API concentration (yaxis) indicates the corresponding $\mathrm{DDO}_{3}$. T-bar represent standard deviation with $\mathrm{n}=3$. 
In order to determine the $\mathrm{O}_{3}$ dosage that achieving $90 \%$ removal of each API in every effluent, the data shown on Figure 1 were fitted with Equation 1. For each API and effluent there are 3 results of each $\mathrm{O}_{3}$ dose applied that stems from the triplicate $\mathrm{O}_{3}$ addition which are fitted as independant points. Selected fitting curves are shown in Figure 2 and all the curves for the 42 APIs in the 6 effluents are shown in Figures S1-S6.

In this study, at lower $\mathrm{O}_{3}$ doses an apparent lag-phase towards degradation was observed for some APIs and it wasn't until higher $\mathrm{O}_{3}$ doses were applied that degradation occurred (Figure 2B). Once the $\mathrm{O}_{3}$ lag-phase dose was surpassed, a decrease of APIs concentrations was observed as $\mathrm{DO}_{3}$ increased which is similar to the curve shape (exponential decay) for APIs which did not show this lagphase. It is our belief, that the lag-phase is a result of the low reactivity of some APIs for direct reaction with $\mathrm{O}_{3}$ in addition to the competition with the wastewater matrix for $\mathrm{O}_{3}$ degradation. Some of the matrix components react directly with $\mathrm{O}_{3}$ and quickly consume the low $\mathrm{O}_{3}$ doses, therefore reducing the chances of $\mathrm{O}_{3}$ reacting with the target compounds. It is only when $\mathrm{O}_{3}$ is added at higher doses than required to satisfy the $\mathrm{O}_{3}$ reactive part of the matrix, that enough $\mathrm{O}_{3}$ remains for the recalcitrant APIs to be degraded either directly or through the secondary pathway which is mediated by $\mathrm{HO}^{\bullet}\left(\mathrm{O}_{3}+\mathrm{H}_{2} \mathrm{O} \rightarrow\right.$ $2 \mathrm{HO}^{\bullet}+\mathrm{O}_{2}$ ), assuming $\mathrm{O}_{3}$ remains in the wastewater long enough to convert to the radical form. To fit the concentration curves of APIs that showed apparent lag of reactivity towards low $\mathrm{O}_{3}$ doses, a variation of Equation 1 was developed and shown as Equation 3 (see Figure S7 for graphical representation).

$$
\begin{aligned}
& I F: \mathrm{DO}_{3}<\mathrm{LagO}_{3} \rightarrow C=C_{o} \\
& I F: \mathrm{DO}_{3}>\mathrm{LagO}_{3} \rightarrow \mathrm{C}=\mathrm{C}_{o} \cdot 10^{-\left(\frac{\mathrm{DO}_{3}-\mathrm{LagO}_{3}}{D}\right)} ; \quad \mathrm{DDO}_{3}=\mathrm{D}+\mathrm{LagO}_{3}
\end{aligned}
$$

The resulting estimated $\mathrm{DDO}_{3}$ values of each API in all the effluents are presented in Table 2. Significant variation is observed in the $\mathrm{DDO}_{3}$ values of a specific API depending on the wastewater effluent matrix. For example, carbamazepine exhibited a low $\mathrm{DDO}_{3}$ of $\sim 2$ $\mathrm{mg} / \mathrm{L}$ in Effluent 3, compared to the high $\mathrm{DDO}_{3}$ of $\sim 10 \mathrm{mg} / \mathrm{L}$ in Effluent 5. This confirms the strong influence exerted by the wastewater matrix components on APIs removal efficiencies with $\mathrm{O}_{3}$. This has also been observed by Benitez et al. (2009) during $\mathrm{O}_{3}$-treatment of pharmaceuticals (including metoprolol and naproxen) in surface and ground water and wastewater. Their results showed higher pharmaceutical removal in surface water (alkalinity $=30 \mathrm{mg} \mathrm{CaCO}_{3} / \mathrm{L}$ ) compared to groundwater (alkalinity=388 $\mathrm{mg} \mathrm{CaCO}_{3} / \mathrm{L}$ ), while 
Table 2: Ozone dose for removal of the first decade of each pharmaceutical in each wastewater and the dose relative to the DOC . (NA* = compound not quantified due to chromatographic shift of peak outside of the MS window; $\mathrm{NA}^{* *}=$ out of range, either $<<$ lowest dose or $>>$ highest dose of ozone applied)

\begin{tabular}{|c|c|c|c|c|c|c|c|c|c|c|c|c|c|}
\hline \multirow[b]{2}{*}{ API } & \multicolumn{6}{|c|}{$\mathrm{DDO}_{3}\left(\mathrm{ppm} \mathrm{O} \mathrm{O}_{3}\right)$} & \multicolumn{5}{|c|}{$\left[\mathrm{DDO}_{3} / \mathrm{DOC}\right]$} & \multirow[b]{2}{*}{ Eff6 } & \multirow[b]{2}{*}{ Ave } \\
\hline & Eff1 & Eff2 & Eff3 & Eff4 & Eff5 & Eff6 & Eff1 & Eff2 & Eff3 & Eff4 & Eff5 & & \\
\hline \multicolumn{14}{|c|}{ Easily degradable } \\
\hline Repaglinide & 2.6 & 3.7 & 1.8 & 4.1 & 8.7 & 1.5 & 0.35 & 0.57 & 0.35 & 0.50 & 0.64 & 0.18 & 0.43 \\
\hline Ezetimibe & 3.2 & 4.6 & 1.5 & 3.8 & 8.0 & 2.0 & 0.43 & 0.71 & 0.29 & 0.47 & 0.58 & 0.24 & 0.45 \\
\hline Diltiazem & 3.6 & 3.7 & 2.2 & 4.3 & 8.0 & 3.9 & 0.48 & 0.57 & 0.42 & 0.53 & 0.58 & 0.47 & 0.51 \\
\hline Eprosartan & 3.2 & 4.9 & 1.9 & 4.5 & 9.1 & 4.2 & 0.43 & 0.76 & 0.37 & 0.55 & 0.66 & 0.50 & 0.55 \\
\hline Trimethoprim & 4.0 & 4.3 & 2.1 & 4.4 & 9.7 & 3.9 & 0.53 & 0.67 & 0.40 & 0.54 & 0.71 & 0.47 & 0.55 \\
\hline Clomipramine & 2.3 & 7.3 & 2.4 & 3.7 & 7.5 & 4.2 & 0.31 & 1.13 & 0.46 & 0.45 & 0.55 & 0.50 & 0.57 \\
\hline Risperidone & 3.5 & 4.7 & 0.9 & 5.5 & 12.1 & 5.0 & 0.47 & 0.73 & 0.17 & 0.68 & 0.88 & 0.60 & 0.59 \\
\hline Hydroxyzine & 3.4 & 5.7 & 1.9 & 4.8 & 10 & 4.8 & 0.45 & 0.88 & 0.37 & 0.59 & 0.73 & 0.57 & 0.60 \\
\hline Codeine & 4.2 & 4.9 & 2.4 & 4.6 & 9.2 & 5.4 & 0.56 & 0.76 & 0.46 & 0.57 & 0.67 & 0.65 & 0.61 \\
\hline Carbamazepine & 5.1 & 5.4 & 2.2 & 4.3 & 10.8 & 3.5 & 0.68 & 0.84 & 0.42 & 0.53 & 0.79 & 0.42 & 0.61 \\
\hline Naproxen & 5.7 & 5.0 & 2.5 & 6.4 & 10 & 3.7 & 0.76 & 0.77 & 0.48 & 0.79 & 0.73 & 0.44 & 0.66 \\
\hline Fexofenadine & 5.2 & 5.8 & 3.0 & 6.5 & 9.1 & 2.9 & 0.69 & 0.90 & 0.58 & 0.80 & 0.66 & 0.35 & 0.66 \\
\hline Orphenadrine & 4.5 & 5.0 & 3.4 & 4.8 & 12.1 & 4.0 & 0.60 & 0.77 & 0.65 & 0.59 & 0.88 & 0.48 & 0.66 \\
\hline Diclofenac & 4.7 & 5.8 & $\mathrm{NA}^{*}$ & 3.5 & 10 & NA* & 0.63 & 0.90 & NA* & 0.43 & 0.73 & $\mathrm{NA}^{*}$ & 0.67 \\
\hline Cilazapril & 4.5 & 7.1 & 2.7 & 5.7 & 11 & 4.0 & 0.60 & 1.10 & 0.52 & 0.70 & 0.80 & 0.48 & 0.70 \\
\hline
\end{tabular}

\begin{tabular}{|c|c|c|c|c|c|c|c|c|c|c|c|c|c|}
\hline Loperamide & 2.0 & 4.5 & $<0.5$ & 5.7 & 13.3 & 8.7 & 0.27 & 0.70 & $\mathrm{NA}^{* *}$ & 0.70 & 0.97 & 1.04 & 0.74 \\
\hline Glimepiride & 7.0 & 7.6 & 3.6 & 6.7 & $>>8.9$ & 0.6 & 0.93 & 1.18 & 0.69 & 0.82 & $\mathrm{NA}^{* *}$ & 0.07 & 0.74 \\
\hline Rosuvastatin & 5.4 & 5.6 & 3.3 & 5 & 14.5 & 4.8 & 0.72 & 0.87 & 0.63 & 0.61 & 1.06 & 0.57 & 0.74 \\
\hline Haloperidole & 4.8 & 7.8 & 1.5 & 6.3 & 11.8 & 5.9 & 0.64 & 1.21 & 0.29 & 0.77 & 0.86 & 0.71 & 0.75 \\
\hline Sulfamethoxazole & 4.8 & 4.5 & 3.6 & 4.5 & 17.6 & NA* & 0.64 & 0.70 & 0.69 & 0.55 & 1.28 & $\mathrm{NA}^{*}$ & 0.77 \\
\hline Verapamil & NA* & 5.4 & $<0.5$ & 5.0 & 10.5 & 7.5 & NA* & 0.84 & NA** & 0.61 & 0.77 & 0.90 & 0.78 \\
\hline Tramadole & 5.7 & 5.8 & 3.4 & 6.3 & 13 & 6.4 & 0.76 & 0.90 & 0.65 & 0.77 & 0.95 & 0.77 & 0.80 \\
\hline Citalopram & 5.0 & 7.8 & 2.0 & 7.1 & 15 & 5.0 & 0.67 & 1.21 & 0.38 & 0.87 & 1.09 & 0.60 & 0.80 \\
\hline Sertraline & 6.4 & 5.2 & 1.7 & 7.9 & 12 & 11.6 & 0.85 & 0.81 & 0.33 & 0.97 & 0.88 & 1.39 & 0.87 \\
\hline Venlafaxine & 5.3 & 6.3 & 3.4 & 6.4 & 16.6 & 9.3 & 0.71 & 0.98 & 0.65 & 0.79 & 1.21 & 1.11 & 0.91 \\
\hline Maprotiline & 7.3 & 6.9 & 4.1 & 8.3 & 13.6 & 7.2 & 0.97 & 1.07 & 0.79 & 1.02 & 0.99 & 0.86 & 0.95 \\
\hline Bisoprolol & 7.2 & 6.0 & 3.3 & 7.3 & 21 & 7.2 & 0.96 & 0.93 & 0.63 & 0.90 & 1.53 & 0.86 & 0.97 \\
\hline Amitriptyline & 7.3 & 9.4 & 3.6 & 8.3 & 13.6 & 7.3 & 0.97 & 1.46 & 0.69 & 1.02 & 0.99 & 0.87 & 1.00 \\
\hline Metoprolol & 6.9 & 6.9 & 3.8 & 7.4 & 18.2 & 8.8 & 0.92 & 1.07 & 0.73 & 0.91 & 1.33 & 1.05 & 1.00 \\
\hline Biperiden & 5.9 & 6.3 & 4.3 & 7.3 & 23 & 7.4 & 0.78 & 0.98 & 0.83 & 0.90 & 1.68 & 0.88 & 1.01 \\
\hline Levonorgestrel & 6.7 & 7.3 & 6.6 & 6.0 & 18.2 & 6.5 & 0.89 & 1.13 & 1.27 & 0.74 & 1.33 & 0.78 & 1.02 \\
\hline Fluoxetine & 6.6 & 6.8 & 3.1 & 7.7 & 20 & 11.3 & 0.88 & 1.05 & 0.60 & 0.95 & 1.46 & 1.35 & 1.05 \\
\hline Irbesartan & 8.7 & 7.7 & 5.4 & 11.5 & 13.7 & 4.3 & 1.16 & 1.19 & 1.04 & 1.41 & 1.00 & 0.51 & 1.05 \\
\hline Bupropion & 8.1 & 8.0 & 5.2 & 9.3 & $>>8.9$ & 12.1 & 1.08 & 1.24 & 1.00 & 1.14 & $\mathrm{NA}^{* *}$ & 1.45 & 1.18 \\
\hline \multicolumn{14}{|c|}{ Recalcitrant towards ozone degradation } \\
\hline Oxazepam & 12.3 & 11.3 & 7.1 & 13.5 & 18.4 & 9.7 & 1.64 & 1.75 & 1.37 & 1.66 & 1.34 & 1.16 & 1.49 \\
\hline Ketoprofen & 13.4 & 12.7 & 5.5 & 13.2 & 23.9 & 9.7 & 1.78 & 1.97 & 1.06 & 1.62 & 1.74 & 1.16 & 1.56 \\
\hline Memantine & 11.4 & 12.8 & 7.8 & 14.5 & 21.3 & 10.2 & 1.52 & 1.98 & 1.50 & 1.78 & 1.55 & 1.22 & 1.59 \\
\hline Ibuprofen & 11.5 & 10.9 & 7.3 & 14.7 & 27 & 10.4 & 1.53 & 1.69 & 1.40 & 1.81 & 1.97 & 1.24 & 1.61 \\
\hline Beclomethasone & 20 & 18 & 5.8 & 12 & $>>8.9$ & 9.2 & 2.66 & 2.79 & 1.12 & 1.47 & $\mathrm{NA}^{* *}$ & 1.10 & 1.83 \\
\hline Atracurium & 3.7 & 6.2 & 4.4 & 11 & 11.1 & 3.9 & 0.49 & 3.13 & 0.85 & 1.35 & 0.81 & 0.47 & 1.18 \\
\hline Flutamide & $>>10.2$ & 25 & 11.7 & 17.9 & $>>8.9$ & 9.4 & $\mathrm{NA}^{* *}$ & 3.87 & 2.25 & 2.20 & $\mathrm{NA}^{* *}$ & 1.12 & 2.36 \\
\hline Fluconazole & 15.1 & 18 & 10.7 & 20 & $>>8.9$ & 22 & 2.01 & 2.79 & 2.06 & 2.46 & $\mathrm{NA}^{* *}$ & 2.63 & 2.39 \\
\hline
\end{tabular}


the effluent containing the lowest DOC and alkalinity had the highest removal among the 3 secondary effluents tested (Benitez et al., 2009).

Based on the above, and in order to categorize the different pharmaceuticals into easily degradable, moderately degradable and recalcitrant towards $\mathrm{O}_{3}$ degradation, the Specific $\mathrm{DDO}_{3}$ value was calculated. Specific $\mathrm{DDO}_{3}$ is calculated by dividing the $\mathrm{DDO}_{3}$ by the effluent DOC $\left[\mathrm{DDO}_{3} / \mathrm{DOC}\right]$. The selection criterion for an API to be characterized as easily degraded was decided to be a $\left[\mathrm{DDO}_{3} / \mathrm{DOC}\right]$ value of $\leq 0.7$. Fifteen out of 42 investigated APIs fulfilled this criterion including repaglinide (antidiabetic), trimethoprim (antibiotic), carbamazepine (antiepileptic) and diclofenac (antiphlogistic) and naproxen (antiphlogistics). Nineteen APIs fulfilled the moderately degradable criterion of $0.7<\left[\mathrm{DDO}_{3} / \mathrm{DOC}\right] \leq 1.4$ including sulfamethoxazole (antibiotic), metoprolol and bisoprolol (beta blockers) and citalopram, amitriptyline, maprotiline, venlafaxine, fluoxetine, bupropion and sertraline (antidepressants). The remaining 8 APIs, such as beclomethasone and the antiphlogistics ketoprofen and ibuprofen, were considered $\mathrm{O}_{3}$-recalcitrant since they had $\left[\mathrm{DDO}_{3} / \mathrm{DOC}\right]>1.4$.

Previous studies of the cited literature (Hollender et al. 2009; Bahr et al.,2010) have also used the $\mathrm{O}_{3}$ dose in relation to the DOC wastewater value to describe the treatment efficiency. In a study conducted by Hollender et al. (2009) on the removal of organic micropollutants from wastewater with $\mathrm{O}_{3}$, which included 24 pharmaceuticals, the fast reacting APIs sulfamethoxazole, diclofenac, carbamazepine and trimethoprim were eliminated at a dose of $0.47 \mathrm{~g} \mathrm{O}_{3} / \mathrm{g}$ DOC (dissolved organic carbon). In our study we found that the same compounds require from 0.55 up to $0.77 \mathrm{~g} \mathrm{O}_{3} / \mathrm{g}$ DOC for $90 \%$ removal. Furthermore, Bahr et al., (2010) reported complete removal of naproxen, diclofenac and carbamazepine at a specific ozone dose of $0.5 \mathrm{~g} \mathrm{O}_{3} / \mathrm{g}$ DOC during ozonation of secondary WWTP effluent. Our study predicts the dosage required for $90 \%$ removal of these APIs to be in the order of 0.61-0.66 $\mathrm{g} \mathrm{O}_{3} / \mathrm{g}$ DOC. While for slow reacting compounds, such as ibuprofen and ketoprofen, a specific ozone dose $>1 \mathrm{~g} \mathrm{O}_{3} / \mathrm{g}$ DOC is required for $>95 \%$ removal according to Bahr et al., 2010. In comparison, our work showed the dosage of ozone required for $90 \%$ removal to be 1.61 and $1.51 \mathrm{~g} \mathrm{O}_{3} / \mathrm{g}$ DOC, respectively, for these two APIs.

The degradation profiles of select APIs in the 6 effluents that follow first order decay with the added $\mathrm{O}_{3}$ (carbamazepine, naproxen) are shown in Figure 2A while Figure 2B depicts the degradation profiles of the APIs that exhibited an apparent lag phase before any significant degradation occurred (beclomethasone, memantine). Intersection of the horizontal line with the $y$-axis in Figures 2 and S1-S6 indicates the $\mathrm{DDO}_{3}$ of the APIs from which it is 
evident that Effluent 5 is the most recalcitrant to $\mathrm{O}_{3}$-treatment as it requires the higher $\mathrm{DDO}_{3}$ for all APIs compared to the other effluents (Figures 2A and 2B).

Based on the data shown in Table 2, the average $\left[\mathrm{DDO}_{3} / \mathrm{DOC}\right]$ for the majority of the APIs is $\leq 1.2$, while only a few exhibit a $\left[\mathrm{DDO}_{3} / \mathrm{DOC}\right]>1.5$. Thus, an $\mathrm{O}_{3}$ dose of $1.4 \mathrm{~g}$ per $\mathrm{g}$ DOC should be sufficient to remove (by at least $90 \%$ ) more than $80 \%$ of the APIs tested in this study. However, in order to remove the most $\mathrm{O}_{3}$-recalcitrant APIs as well, a twice as high $\mathrm{O}_{3}$ dose $\left(\left[\mathrm{DDO}_{3} / \mathrm{DOC}\right]>2.4 \mathrm{~g} \mathrm{O}_{3}\right.$ per $\left.\mathrm{g} \mathrm{DOC}\right)$ is needed which results in a significantly more costly treatment process.

\subsection{Effect of chemical structure of APIs on $\mathrm{O}_{3}$ reactivity}

The chemical structure of each API and the functional groups comprising it determine whether an API would be easy or difficult to degrade with $\mathrm{O}_{3}$. Due to its electronic configuration, $\mathrm{O}_{3}$ can perform different types of reactions in water including oxidation reactions, cycloadditions and electrophilic substitution reactions (Beltrán, 2004). Easily degradable APIs (relatively low $\left[\mathrm{DDO}_{3} / \mathrm{DOC}\right]$ values) are characterized by the presence of electron-rich functional groups and they mainly react readily with $\mathrm{O}_{3}$ through electrophilic substitution. These functional groups include $\mathrm{C}=\mathrm{C}$ double bonds (found in eprosartan, carbamazepine), tertiary amines (repaglinide, clomipramine), aniline (dicofenac), phenol (iezetimibe) and methoxy groups (trimethoprim, diltiazem, naproxen) (Hoigne and Bader, 1976; Huber et al., 2003; Huber et al., 2005; Nakada et al., 2007, Hollender et al., 2009).

APIs which are poorly removed (relatively high $\left[\mathrm{DDO}_{3} / \mathrm{DOC}\right]$ values) generally contain electron-withdrawing functional groups, such as fluoro (flutamide, fluconazole), nitro (flutamide), chloro (beclomethasone), amide (flutamide) and carboxyl (ibuprofen, ketoprofen) (Hey et al., 2012; Nakada et al., 2007; Acero et al., 2000; Hollender et al., 2011). Electron withdrawing groups reduce $\mathrm{e}^{-}$density from the APIs structure inhibiting electrophilic substitution reactions from occurring. In addition, the electronegative groups themselves are less likely to react with $\mathrm{O}_{3}$ and thus cause a shielding effect.

Some easily degradable APIs such as carbamazepine and diclofenac also contain electron-withdrawing functional groups (amide in carbamazepine, chloro and carboxylic acid in diclofenac) but remain $\mathrm{O}_{3}$-reactive, inferring the presence and position of the high edensity functional groups, such as the aromatic amine (diclofenac) and $\mathrm{C}=\mathrm{C}$ double bond (carbamazepine) (Nakada et al., 2007), counteracts the inhibitory effect . 
Ibuprofen possesses no electron-rich functional group and is recalcitrant towards $\mathrm{O}_{3}$ treatment (Huber et al., 2005) however can be adequately removed through intense biological treatment (e.g. (Fick et al., 2011; Falås et al., 2012a, 2012b)). In addition, effective oxidative removal of $\mathrm{O}_{3}$-resistant APIs may be possible through the hydroxyl radical pathway (Antoniou et al., 2008).

\section{Conclusions}

- When the effect of $\mathrm{O}_{3}$ dose on degradation of 42 APIs in 6 different WWTP effluents was investigated, a large variability between APIs and effluents types was observed.

- The estimated $\mathrm{DDO}_{3}$ of a specific API, used to evaluate the necessary $\mathrm{O}_{3}$ dose to achieve reduction by one decade, varied significantly among the effluents investigated.

- $\mathrm{DDO}_{3}$ was correlated with the effluent $\mathrm{DOC}$ by calculating the $\mathrm{DDO}_{3} / \mathrm{DOC}$ for each API in every effluent. This enabled ranking of the different APIs into easily degradable, moderately degradable and recalcitrant to $\mathrm{O}_{3}$-treatment categories.

- Following this practice, the required $\mathrm{O}_{3}$ dose can be predicted based on the target pharmaceutical and the matrix component of the wastewater (DOC) to be treated.

- $\mathrm{An}_{3}$ dose of $1.4 \mathrm{~g}$ per g DOC removed (by at least $90 \%$ ) more than $80 \%$ of the APIs tested in this study. To remove the most $\mathrm{O}_{3}$-recalcitrant APIs a dose in the order of 2.4 $\mathrm{g} \mathrm{O}_{3}$ per g DOC is required.

\section{Acknowledgements}

The authors are grateful to the staff and process engineers of the Swedish WWTPs Källby, Björnstorp, Öresundsverket, Sjölunda, and Nykvarnsverket for providing the wastewater samples.

\section{References}

Acero, J.L., Stemmler, K., von Gunten, U., 2000. Degradation kinetics of atrazine and its degradation products with ozone and $\mathrm{OH}$ radicals: A predictive tool for drinking water treatment. Environmental Science and Technology 34, 591-597.

Antoniou, M.G., Andersen, H.R., 2012. Evaluation of pre-treatments for inhibiting bromate formation during ozonation. Environmental Technology. 33(15), 1747-1753, 
Antoniou, M.G., Shoemaker, J.A., De La Cruz, A.A., Dionysiou, D.D., 2008. Unveiling new degradation intermediates/pathways from the photocatalytic degradation of microcystin-LR, Environmental Science and Technology 23, 8877-8883.

Bader, H., Hoigne, J., 1981. Determination of ozone in water by the indigo method. Water Research 15(4), 449-456.

Bahr, C., Schumacher, J., Ernst, M., Luck, F., Heinzmann, B., Jekel, M., 2007. SUVA as control parameter for the effective ozonation of organic pollutants in secondary effluent. Water Science and Technology 55(12), 267-274.

Beltrán, F. J., 2004. Ozone reaction kinetics for water and wastewater systems, Lewis Publishers, CRC Press LLC.

Benner, J., Ternes, T.A., 2009. Ozonation of metoprolol: Elucidation of oxidation pathways and major oxidation products. Environmental Science and Technology 43(14), 5472-5480.

Benitez, F.J., Acero, J.L., Real, F.J., Roldan, G., 2009. Ozonation of pharmaceutical compounds: Rate constants and elimination in various water matrices. Chemosphere 77, 5359.

Bolton, J.R., Bircher, K.G., Tumas, W., Tolman, C.A., 2001. Figures-of-merit for the technical development and application of advanced oxidation technologies for both electricand solar-driven systems. Pure and Applied Chemistry 73(4), 627-637.

Buffle, M.O., Schumacher, J., Salhi, E., Jekel, M., von Gunten, U., 2006a. Measurement of the initial phase of ozone decomposition in water and wastewater by means of a continuous quench-flow system: Application to disinfection and pharmaceutical oxidation. Water Research 40(9), 1884-1894.

Buffle, M.O., Schumacher, J., Meylan, S., Jekel, M., Von Gunten, U., 2006b. Ozonation and advanced oxidation of wastewater: Effect of $\mathrm{O} 3$ dose, $\mathrm{pH}$, DOM and HO.-scavengers on ozone decomposition and HO• generation. Ozone: Science and Engineering 28(4), 247-259.

Dodd, M.C., Buffle, M.O., Von Gunten, U., 2006. Oxidation of antibacterial molecules by aqueous ozone: Moiety-specific reaction kinetics and application to ozone-based wastewater treatment. Environmental Science and Technology 40(6), 1969-1977. 
Falås, P., Andersen, H.R., Ledin, A., la Cour Jansen, J., 2012a. Occurrence and reduction of pharmaceuticals in the water phase at Swedish wastewater treatment plants. Water Science and Technology. 66(4) p 783-791 (2012).

Falås, P., Baillon-Dhumez, A., Andersen, H.R., Ledin, A., la Cour Jansen, J., 2012b. Suspended biofilm carrier and activated sludge removal of acidic pharmaceuticals. Water Research 46, 1167-1175.

Fick, J., Lindberg, R.H., Tysklind, M., Larsson, D.G., 2010. Predicted critical environmental concentrations for 500 pharmaceuticals. Regulatory toxicology and pharmacology : RTP $58(3), 516-523$.

Fick, J., Lindberg, R.H., Kaj, L., Brorström-Lundén, E., 2011. Results from the Swedish National Screening Programme 2010. Subreport 3. Pharmaceuticals. (www.ivl.se, Can be ordered with e-mail to: publicationservice@ivl.se,))

Gerrity, D., Snyder, S., 2011. Review of ozone for water reuse applications: Toxicity, regulations, and trace organic contaminant oxidation. Ozone: Science and Engineering 33(4), 253-266.

Grabic, R., Fick, J. Lindberg, R.H., Fedorova, G., Tysklind, M., 2012. Multi-residue method for trace level determination of pharmaceuticals in environmental samples using liquid chromatography coupled to triple quadrupole mass spectrometry. Talanta 100, 183-195.

GraphPad Prism 5.03 GraphPad Software, Inc. 2009, 2236 Avenida de la Playa, La Jolla, CA 92037, USA; software available at http://www.graphpad.com.

Hansen, K.M.S., Andersen, H.R., Ledin, A., 2010. Ozonation of estrogenic chemicals in biologically treated sewage. Water Science and Technology 62(3), 649-657.

Hey, G., Grabic, R., Ledin, A., la Cour Jansen, J., Andersen, H.R., 2012. Oxidation of pharmaceuticals by chlorine dioxide in biologically treated wastewater. Chemical Engineering Journal 185-186, 236-242.

Hoigne, H., Bader, H., 1983). Rate constants of reactions of ozone with organic and inorganic compounds in water. II. Dissociating organic compounds. Water Research 17(2), 185-194. 
Hollender, J., Zimmermann, S.G., Koepke, S., Krauss, M., McArdell, C.S., Ort, C., Singer, H., Von Gunten, U., Siegrist, H., 2009. Elimination of organic micropollutants in a municipal wastewater treatment plant upgraded with a full-scale post-ozonation followed by sand filtration. Environmental Science and Technology 43(20), 7862-7869.

Huber, M.M., Canonica, S., Park, G.Y., von Gunten, U., 2003. Oxidation of pharmaceuticals during ozonation and advanced oxidation processes. Environmental Science and Technology 37(5), 1016-1024.

Huber, M.M., Göbel, A., Joss, A., Hermann, N., Löffler, D., McArdell, C.S., Ried, A., Siegrist, H., Ternes, T.A., von Gunten, U., 2005. Oxidation of pharmaceuticals during ozonation of municipal wastewater effluents: A pilot study. Environmental Science and Technology 39(11), 4290-4299.

Huerta-Fontela, M., Galceran, M.T., Ventura, F., 2011. Occurrence and removal of pharmaceuticals and hormones through drinking water treatment. Water Research 45(3), $1432-1442$.

Hörsing, M., Ledin, A., Grabic, R., Fick, J., Tysklind, M., la Cour Jansen, J., Andersen, H.R., 2011. Determination of sorption of seventy-five pharmaceuticals in sewage sludge. Water Research 45, 4470-4482.

Kim, I., Tanaka, H., 2011. Energy consumption for PPCPs removal by O3 and O3/UV. Ozone: Science and Engineering 33(2), 150-157.

Kolpin, D.W., Furlong, E.T., Meyer, M.T., Thurman, E.M., Zaugg, S.D., Barber, L.B., Buxton, H.T., 2002. Pharmaceuticals, hormones, and other organic wastewater contaminants in U.S. streams, 1999-2000: a national reconnaissance. Environmental Science and Technology 36, 1202-1211.

Lee, Y., von Gunten, U., 2010. Oxidative transformation of micropollutants during municipal wastewater treatment: Comparison of kinetic aspects of selective (chlorine, chlorine dioxide, ferrateVI, and ozone) and non-selective oxidants (hydroxyl radical). Water Research 44(2), $555-566$.

Nakada, N., Shinoharaa, H., Murataa, A., Kiria, K., Managakia, S., Satob, N., Takadaa, H., 2007. Removal of selected pharmaceuticals and personal care products (PPCPs) and 
endocrine-disrupting chemicals (EDCs) during sand filtration and ozonation at a municipal sewage treatment plant. Water Research 41, 4373-4382.

Richardson, S.D., 2010. Environmental mass spectrometry: Emerging contaminants and current issues. Analytical Chemistry 82(12), 4742-4774.

Ternes, T.A., 1998. Occurrence of drugs in German sewage treatment plants and rivers, Water Research 32, 3245-3260.

Ternes, T.A., Stüber, J., Herrmann, N., McDowell, D., Ried, A., Kampmann, M., Teiser, B., 2003. Ozonation: a tool for removal of pharmaceuticals, contrast media and musk fragrances from wastewater? Water Research 37(8), 1976-1982.

Zimmermann, S.G., Wittenwiler, M., Hollender, J., Krauss, M., Ort, C., Siegrist, H., von Gunten, U., 2011. Kinetic assessment and modeling of an ozonation step for full-scale municipal wastewater treatment: Micropollutant oxidation, by-product formation and disinfection. Water Research 45(2), 605-617. 
